\title{
Isolation and Characterization of Nitrogen Fixing Bacteria from Babchi (Psorolea corylifolia L.) and Testing them for Plant Growth Promotion Traits in vitro
}

\author{
Mahesh Dattatry Shengepallu, Ravindra Tatyaram Gaikwad, \\ Visvas Anandrao Chavan and Yumlembam Rupert Anand*
}

\author{
Department of Plant Pathology and Agricultural Microbiology, Mahatma Phule Krishi \\ Vidyapeeth, Rahuri-413 722 (M.S.), India
}

*Corresponding author

A B S T R A C T

\section{Keywords}

Babchi (Psorolea corylifolia L.), in vitor

Article Info

Accepted:

07 February 2018

Available Online:

10 March 2018
Two isolates of Rhizobium were isolated from Babchi (Psorolea corylifolia) root nodules, which showed positive tests for catalase test, oxidase test, nitrate reduction test and starch hydrolysis while negative test for methyl red test, Voges-Proskauer test, urease test, gelatin lignification test, methylene blue test, urease test, gelatin liquification test, methylene blue test, lactose test, citrate utilization test and hydrogen sulphide production test. The isolate PCRI-1 and PCRI-2 exhibited a great variation in N fixation by of $24.35 \mathrm{mg} / \mathrm{g}$ and 20.70 $\mathrm{mg} / \mathrm{g}$ of sucrose consumed, respectively. The amount of IAA produced by these isolates was $37.73 \mu \mathrm{g} / \mathrm{ml}$ and $32.40 \mu \mathrm{g} / \mathrm{ml}$ respectively. These isolates showed variation in $\mathrm{PO}_{4}$ solubilization efficiency in the range of 19.1 to 17.8 per cent, with solubilization zone of $6.2 \mathrm{~mm}$ and $4.2 \mathrm{~mm}$, respectively. Its characterization and testing of plant growth promotion traits is the first attempt from the state of Maharashtra, from root nodules of Babchi.

\section{Introduction}

Psoralea corylifolia (Bakuchi), which belongs to the Leguminosae family, is a medicinal plant of immense biological importance due to its magical effects against several skin disease such as psoriasis, leukoderma, and leprosy. This plant is also pharmacologically studied for its chemoprotective, antioxidant, antimicrobial, and anti-inflammatory properties (Khushboo et al., 2010). The seed powder and paste are used in indigenous medicine as laxative, aphrodisiac, anthelmintic, diuretic stomachic, stimulant and diaphoretic in febrile conditions (Ambreen et al., 2013). The root nodulating bacteria, also known as plant growth promoting rhizobacteria, are in symbiotic association with leguminous plants. These symbiotic bacteria along with the legume give maximum contribution of global nitrogen fixation. Rhizobiaceae family contains six genera viz., Rhizobium, Sinorbizobium, MesoRhizobium, AlloRhizobium, AzoRhizobium and BradyRhizobium (Okazaki et al., 2004). Rhizobiacteria effectively colonize plant root and increases plant growth by production of various plant growth hormones, B-solubilizing 
activity, $\mathrm{N}_{2}$ fixation and biological control activity (Deshwal et al., 2011). The Rhizobium legume symbiosis in superior to other nitrogen fixing systems due to its high potential (Sanaa and Fawziah, 2005). Dispersion of host plants to new geographical locations might serve as a major source for these new rhizobia species. Only $57 \%$ of 650 genera of leguminous plants have been studied for nodulation. Exploration of large number of legume species can potentially lead to the identification of many more rhizobial species. Therefore, identification and exploration of such potential rhizobia with plant growth promoting properties will be useful for sustainable agriculture.

\section{Materials and Methods}

\section{Collection of root nodules and isolation of} Rhizobium

For the isolation of nitrogen fixing Rhizobium the root-nodules of Babchi plant was collected from AICRP on Medicinal, Aromatic Plants and Betelvine Project, M.P.K.V., Rahuri. The collected nodules were washed under tap water to remove adhering soil particles. The healthy, fresh, plump and pinkish root nodules were selected and surface sterilized with 95 per cent ethanol for 5-10 sec., followed by 3 $\%(\mathrm{v} / \mathrm{v})$ sodium hypochloride solution for 2-4 min and washed with sterile distilled water for 3-4 times. The selected nodules were crushed with the help of sterilized glass rod to obtain a milky suspension of bacteriods. these were streaked on yeast extract mannitol agar (YEMA pH 7.0) media plantes and incubated at $3^{\circ} \mathrm{C}$ (Aneja, 2003). After two days of incubation, colonies of nitrogen fixing bacteria were obtained.

\section{Confirmation of nitrogen fixing bacteria as Rhizobium}

All the six bacterial isolates obtained from the rot nodules of Babchi were tested for their growth on comes red yeast extract manitol agar (RYEMA), Lactose agar (LA) for their further an formation as Rhizobium isolates. As Rhizobium colonies did not absorb Congo red colour while common contaminants absorb Congo red colour in this way Rhizobium was differentiated. On the lactose agar medium presence of yellow colour confirms the presence of common contaminant Agrobacterium sp. white absorbance of yellow colour indicates presence of Rhizobium sp. as these Rhizobium does not convert lactose to 3 leaf lactose. This is one of ways to differentiate Rhizobium and other common contaminants.

\section{Characterization of Rhizobium isolates}

The Rhizobium isolates were characterized morphologically, physiologically and biochemically, morphological characterization includes colony colour shape, diameter, margin, elevation and consistency as well as shape of bacteria, mortility and gram reaction as pe standard procedure of Aneja (2003). Physiological characterization includes growth at different range of temperature and $\mathrm{pH}$ value, biochemical characterization includes methyl red-Voges-Proskauer test, catalase test, oxidase test, urease test, nitrate reduction test, starch hydrolysis test, gelatin liquification test, methylene blue test, lactose test, citrate utilization test and hydrogen sulphide production test.

\section{Efficacy of Rhizobium isolates for plant growth promotion traits}

The plant growth promotion traits viz., nitrogen fixation, phosphate solubilization and indole acetic acid production were also tested for the Rhizobium isolates.

Nitrogen fixation: The test Rhizobium isolates were screened for their nitrogen fixation ability on the basis of per $\mathrm{mg}$ of sucrose consumed and the amount of nitrogen fixed 
was estimated by Micro-Kjeldhal's method (Jackson, 1976).

Phosphate solubilization: The plates were prepared with Pikovaskaya's medium. The test Rhizobium isolates was streaked on the media of plates and incubated in an incubator at $28^{\circ} \mathrm{C}$ for 7-8 days. The presence of clearing zone around the test Rhizobium isolates was used as indicator for positive phosphate solubilization.

Indole acetic acid (IAA) production: The test Rhizobium isolates were grown in $25 \mathrm{ml}$ of nutrient broth amended with $50 \mu / \mathrm{ml}$ of treyptophan in $100 \mathrm{ml}$ flank for $24 \mathrm{hrs}$ at $28^{\circ} \mathrm{C}$ on rotary shaker. After completion of incubation period test cultures were harvested by centrifuged at $10,000 \mathrm{rpm}$ for $25 \mathrm{~min}$ at $4^{\circ} \mathrm{C}$. Two-three drops of arthophosphoric acid was added to $2 \mathrm{ml}$ of cell free supernatant and the development of colour was observed. The presence of a pink colour indicates positive reaction for middle acetic acid production.

\section{Results and Discussion}

The six bacteria isolates were tested for the growth on Congo red yeast extract, mannitol agar and lactose agar mediums. Out of six isolates, isolate-1 (PCRI-1) and isolate-2 (PCRI-2) did not absorb the Congo red colour and maintain their original milky white colour when grown on CRYEMA medium plates (Table 1). While, isolate-3 (PCRI-3), isolates (PCRI-4), isolate-5 (PCRI-5) and isolate-6 (PCRI-6) absorbed red colour of Congo when grown on CRYEMA medium plates. When these six isolates were grown on lactose agar, isolate-1 (PCRI-1) and isolate-2 (PCRI-2) did not shown any yellow colour of colonies while isolate-3 (PCRI-3), isolate-4 (PCRI-4), isolate5 (PCRI-5) and isolate-6 (PCRI-6) shown yellow colour and around the colonies of these isolates. It clearly initiated that isolate-1 (PCRI-1) and isolate-2 (PCRI-2) were of Rhizobium sp. while rest of the isolates no 3 (PCRI-2), 4 (PCRI-4), 5 (PCRI-5) and 6
(PCRI-6) were contaminant and may be Agrobacterium sp. Thus, finally two isolates were confirmed to be of Rhizobium genus.

\section{Morphological characterization}

The Rhizobium isolates PCRI-1 and PCRI-2 were characterized morphologically on YEMA media plates (Table 2).

The Rhizobium isolate PCRI-1 was white translucent in colour, circular in shape and have colony diameter of 2-3 mm with entire margin, raised (convex) and sticky mucold in consistency; whereas, isolate PCRI-2 was milky while translucent, circular in shape with 2-4 $\mathrm{mm}$ in colony diameter, locate margin and convex in elevation with sticky mucold consistency. Both the isolates were rod shaped, motile and gram negative in reactions.

\section{Physiological characterization}

The Rhizobium isolates PCRI-1 and PCRI-2 were tested against different temperature ranging from $15^{\circ} \mathrm{C}$ to $45^{\circ} \mathrm{C}$ (Table 3). The isolate PCRI-1 required optimum temperature of $35-40^{\circ} \mathrm{C}$ for its growth, while the isolate PCRI-2 required optimum temperature of 30$35^{\circ} \mathrm{C}$ and both were merophilic in nature. Both the isolates were also tested against different YEMA media with variant $\mathrm{pH}$ values ranging from 4.5 to $8.5 \mathrm{pH}$. The optimum $\mathrm{pH}$ ranges in between 6.5 to 7.5 , which indicates that they were neutral phallic in nature.

\section{Biochemical characterization}

Biochemical characterization of the Rhizobium isolates were carried out for Indole test, Methyl red and Voges-Proskauer test (MRVP test), Catalase test, Oxidase test, Nitrate reduction test, Urease test, Starch hydrolysis, Gelatin liquification, Methylene blue test, Lactose assay, Citrate utilization test and $\mathrm{H}_{2} \mathrm{~S}$ production test for differentiation of the isolated strains of Rhizobium (Table 4). 
Table.1 Confirmation tests for bacterial isolates

\begin{tabular}{|c|c|c|c|c|c|}
\hline \multirow[t]{2}{*}{$\begin{array}{l}\text { Bacterial } \\
\text { isolates }\end{array}$} & \multicolumn{2}{|c|}{$\begin{array}{c}\text { Growth on differential } \\
\text { media }\end{array}$} & \multirow{2}{*}{$\begin{array}{l}\text { Absorption } \\
\text { of red colour } \\
\text { on CRYRMA } \\
\text { media }\end{array}$} & \multirow{2}{*}{$\begin{array}{c}\text { Absorption } \\
\text { of yellow } \\
\text { colour on } \\
\text { lactose agar } \\
\text { media }\end{array}$} & \multirow[t]{2}{*}{$\begin{array}{l}\text { Possible } \\
\text { organisms }\end{array}$} \\
\hline & CRYRMA & $\mathbf{L A}$ & & & \\
\hline PCRI-1 & ++ & -- & -ve & -ve & Rhizobium sp. \\
\hline PCRI-2 & ++ & -- & - ve & $-\mathrm{ve}$ & Rhizobium sp. \\
\hline PCRI-3 & ++ & ++ & +ve & +ve & Agrobacterium sp. \\
\hline PCRI-4 & ++ & ++ & +ve & +ve & Agrobacterium sp. \\
\hline PCRI-5 & ++ & ++ & +ve & +ve & Agrobacterium sp. \\
\hline PCRI-6 & ++ & ++ & +ve & +ve & Agrobacterium sp. \\
\hline $\begin{array}{l}++=\text { Full gro } \\
\text { Presence of re } \\
\text { Absence of re } \\
\text { Presence of ye } \\
\text { Absence of ye }\end{array}$ & $\begin{array}{l}\text { lour } \\
\text { lour } \\
\text { colour } \\
\text { colour }\end{array}$ & $\begin{array}{l}\text { owth } \\
=\text { Positive } \\
=\text { Negativ } \\
=\text { Positive } \\
=\text { Negativ }\end{array}$ & $\begin{array}{l}\text { test (+ve) } \\
\text { test (-ve) } \\
\text { test (+ve) } \\
\text { test (-ve) }\end{array}$ & & \\
\hline
\end{tabular}

Table.2 Morphological characterization of Rhizobium isolates

\begin{tabular}{|c|c|c|c|c|c|c|c|c|c|c|}
\hline \multirow{2}{*}{$\begin{array}{l}\text { Sr. } \\
\text { No. }\end{array}$} & \multirow{2}{*}{$\begin{array}{l}\text { Rhizobium } \\
\text { isolate }\end{array}$} & \multicolumn{6}{|c|}{ Colony morphology } & \multicolumn{3}{|c|}{ Bacterial morphology } \\
\hline & & Colour & Shape & Diameter (mm) & Margin & Elevation & Consistency & Shape & Motility & $\begin{array}{c}\text { Gram } \\
\text { reaction }\end{array}$ \\
\hline 1. & PCRI-1 & $\begin{array}{l}\text { White and } \\
\text { translucent }\end{array}$ & Circular & $2-3$ & $\begin{array}{l}\text { Entire, } \\
\text { Smooth }\end{array}$ & Convex & $\begin{array}{l}\text { Sticky and } \\
\text { Mucoid }\end{array}$ & Rod & Motile & Negative \\
\hline 2. & PCRI-2 & $\begin{array}{l}\text { Milky white } \\
\text { and } \\
\text { translucent }\end{array}$ & Circular & $2-4$ & $\begin{array}{l}\text { Lobate } \\
\text { smooth } \\
\text { spreading } \\
\text { type }\end{array}$ & Convex & $\begin{array}{l}\text { Sticky and } \\
\text { Mucoid }\end{array}$ & Rod & Motile & Negative \\
\hline
\end{tabular}


Table.3 Effect of different temperature on the growth of Rhizobium isolates

\begin{tabular}{|c|c|c|c|c|c|c|c|c|c|c|}
$\begin{array}{l}\text { Sr. } \\
\text { No. }\end{array} \begin{array}{c}\text { Isolate } \\
\text { no. }\end{array}$ & $\mathbf{1 5}$ & $\mathbf{2 0}$ & $\mathbf{2 5}$ & $\mathbf{3 0}$ & $\mathbf{3 5}$ & $\mathbf{4 0}$ & $\mathbf{4 5}$ & $\begin{array}{r}\text { Optimum } \\
\text { temperature } \\
\text { requirement }\end{array}$ & Classification \\
\hline $\mathbf{1}$ & PCRI-1 & + & + & + & + & ++ & ++ & + & $35-40^{\circ} \mathrm{C}$ & Mesophile \\
\hline 2 & PCRI-2 & + & + & + & ++ & ++ & + & - & $30-35^{\circ} \mathrm{C}$ & Mesophile \\
\hline
\end{tabular}

++ : Full growth, +: Scanty growth, --: No growth

Table.4 Biochemical characterization of Rhizobium isolates PCRI-1

\begin{tabular}{|c|c|c|c|}
\hline Sr. No. & Biochemical test & PCRI-1 & PCRI-2 \\
\hline 1. & Indole test & - & - \\
\hline 2. & Methyl red test & - & - \\
\hline 3. & Voges-Proskauer test & - & - \\
\hline 4. & Catalase test & + & + \\
\hline 5. & Oxidase test & + & + \\
\hline 6. & Nitrate reduction test & + & + \\
\hline 7. & Urease test & - & - \\
\hline 8. & Starch hydrolysis test & + & + \\
\hline 9. & Gelatin liquification test & - & - \\
\hline 10. & Methylene blue test & - & - \\
\hline 11. & Lactose assay & - & - \\
\hline 12. & Citrate utilization test & - & - \\
\hline 13. & $\mathrm{H}_{2} \mathrm{~S}$ production test & - & - \\
\hline
\end{tabular}

The Rhizobium isolate PCRI-1 and PCRI-2 showed positive reaction against catalase, oxidase, nitrate reduction and starch hydrolysis test while negative reactions for rest of the tests conducted. On the basis of these characterization these isolates tentatively belongs to Rhizobium leguminosarum and which further needs to be further confirmed by molecular techniques.

Plant growth promotion traits of Rhizobium isolates

The Rhizobium isolates PCRI-1 and PCRI-2 were also tested for their plant growth promotion traits viz., nitrogen fixation, phosphate solubilization, indole acetic production in vitro.

\section{Nitrogen fixation}

The amount of nitrogen fixed by Rhizobium isolates during incubation in broth culture indicated that the Rhizobium isolate PCRI-1 fixed nitrogen $24.35 \mathrm{mg} / \mathrm{g}$ of sucrose consumed whereas isolate PCRI-2 fixed nitrogen $20.70 \mathrm{mg} / \mathrm{g}$ of sucrose consumed. It clearly indicates that both isolates possessed nitrogen fixation capacity with little variation among them.

\section{Phosphate solubilization}

The per cent $\mathrm{PO}_{4}$ solubilization by Rhizobium isolates PCRI-1 and PCRI-2 during incubation in both cultures was 19.1 and 17.8 per cent, respectively with solubilization of 
$6.2 \mathrm{~mm}$ and $4.2 \mathrm{~mm}$, respectively. It clearly indicates that both the isolates exhibited phosphate solubilization ability.

\section{Indole acetic acid production}

The Rhizobium isolates PCRI-1 and PCRI-2 when tested for their indole acetic production test indicated that both the isolates have ability of indole acetic acid production. The isolate PCRI-1 production $37.73 \mu \mathrm{g} / \mathrm{ml}$ of IAA whereas isolate PCRI-2 produced 32.40 $\mu \mathrm{g} / \mathrm{ml}$ of IAA. These results clearly indicated that both the isolates possessed plant growth promotion activity to namely, nitrogen fixation, phosphose solubilization and indole acetic acid production.

This is the first attempt from the state of Maharashtra to isolate Rhizobium from root nodules of Babchi its characterization and testing the plant growth promotion traits.

Out of the six isolates, from the root nodules of Babchi, PCRI-1 and PCRI-2 were unable to grow on Lactose agar media and rest of isolates viz. isolate PCRI-3, PCRI-4, PCRI-5 and PCRI-6 showed full growth. Results also showed that on CRYEMA media isolate1 and 2 did not absorb the Congo red colour which clearly indicated that these isolates were of Rhizobium. Similar results were earlier reported by Deshwal and Chaubey (2014) and Shetta et al., (2011). Both bacterial isolate viz., PCRI- 1 and PCRI- 2 were motile, Gram negative and rod shaped. The morphological characterization indicated that isolates PCRI1 was dull white in colour, entire in margin, convex in elevation and circular in form. The isolate PCRI-2 was whitish in colour, lobate in margin, elevated in elevation and irregular and spreading type of form. The isolate PCRI1 and PCRI-2 showed pin head type small sized colonies on CRYEMA and secreted high mucilaginous compound around the colonies as just mention elsewhere (Arora et al., 2001; Deshwal et al., 2014). The Rhizobium isolates showed optimum temperature requirement of $35-40^{\circ} \mathrm{C}$ and the optimum $\mathrm{pH}$ of 6.5-7.5. Similar observation was made by Baoling et al., (2007), Deora et al., (2010) and Singh et al., (2011). Both isolates showed positive results for catalase test, oxidase test, nitrate reduction test and starch hydrolysis test while negative results for indole test, MRVP test, urease test, gelatin liquification test, methylene blue test, lactose test, citrate utilization and $\mathrm{H} 2 \mathrm{~S}$ production test. Similar results were obtained by many researchers Deora and Singhal (2010), Bhattacharya et al., (2013), Rajpoot and Panwar (2013), Patil et al., (2014). On the basis of cultural, morphological, physiological and biochemical characterization shown by the isolate PCRI-1 and PCRI-2, they were tentatively identified as Rhizobium leguminosarum. However for their exact identification, molecular characterization and cross inoculation studies are necessary. However, Prabha et al., (2013) made attempt to isolate Rhizobium from Psorolea corylifolia L. and isolated two species viz. Rhizobium leguminosarum and Ensifer meliloti. In our study we have isolated only one species i.e. Rhizobium leguminosarum. As far as the plant growth promotion traits are concerned the Rhizobium isolate PCRI-1 was found to be superior in terms of indole acetic acid production, nitrogen fixation and phosphate solubiization. Satyanandam et al., (2014) reported that some Rhizobium species were found to be involved in phosphate solubilization and this ability of phosphate solubilization by the Rhizobium strains could be exploited as PGPR. Gupta et $a l$. , (2014) studied the isolation of rhizobactor and selection of plant growth promoting bacteria via their biochemical screening like $\mathrm{N}_{2}$ fixation, phosphate solubilization and indole acetic acid production. On the basis of in vitro and in vivo experiment, both the isolate seems to be promising to have 
beneficial effect on the plant growth promoting parameters of Babchi and the coinoculation of these two Rhizobium isolates has most significant effect over control.

\section{Acknowledgments}

The authors are thankful to the field of Department of Plant Pathology and Agricultural Microbiology, M.P.K.V., Rahuri for bio constant support the said research work as well as to the University authority.

\section{References}

Ambreen Huma, Ghazala H. Rizwani, Muhammed Usman and Maryam Ahmed (2013) Pharmacognostic evaluation of herbomineral formulation (ALG-06) used in Vitiligo. Int $\mathbf{J}$ Pharm Pharm Sci, Vol 5, Issue 1, 91-95.

Chandra Prabha, D. K. Maheshwari, and Vivek K. Bajpai (2013) Diverse role of fast growing rhizobia in growth promotion and enhancement of psoralen content in Psoralea corylifolia L. Pharmacogn Mag. 2013 Oct-Dec; 9(Suppl 1): S57-S65. doi: 10.4103/0973-1296.117870.
Deshwal, V.K., Vig, K., Amisha, D. M., Yadav, P., Bhattacharya, D and Verma, M. (2011) Synergistic effects of the inoculation with plant growthpromoting Rhizobium and Pseudomonas on the performance of Mucuna, Annals of Forestry. 19(1): 13-20.

Khushboo, P.S., Jadhav, V.M., Kadam, V.J. and N. S. Sathe (2010) Psoralea corylifolia Linn._-Kushtanashini". Pharmacogn Rev. 4(7): 69-76. doi: 10.4103/0973-7847.65331.

Khushboo, P.S., Jadhav, V.M., Kadam, V.J. and N. S. Sathe (2010) Psoralea corylifolia Linn.- "Kushtanashini". Pharmacogn Rev. 4(7): 69-76. doi: 10.4103/0973-7847.65331.

Okazaki S, Sugawara M, Minamisawa K. (2004) Bradyrhizobium elkanii rtxC gene is required for expression of symbiotic phenotypes in the final step of rhizobitoxine biosynthesis. Appl Environ Microbiol; 70:535-541.

Sanaa, M.E.D. and Fawziah, S.A.S. 2005. Role of some chemical compounds on the detoxification of Rhizobium leguminosarum biovar vicia by some Heavy Metals. Pak. J. Biol. Sci. 8: 1693-1698.

\section{How to cite this article:}

Mahesh Dattatry Shengepallu, Ravindra Tatyaram Gaikwad, Visvas Anandrao Chavan and Yumlembam Rupert Anand. 2018. Isolation and Characterization of Nitrogen Fixing Bacteria from Babchi (Psorolea corylifolia L.) and Testing them for Plant Growth Promotion Traits in vitro. Int.J.Curr.Microbiol.App.Sci. 7(03): 441-447.

doi: https://doi.org/10.20546/ijcmas.2018.703.052 